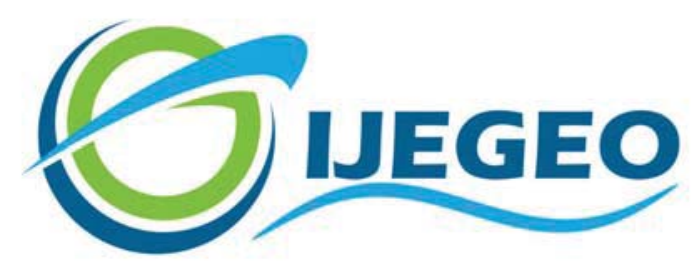

International Journal of Environment and Geoinformatics (IJEGEO) is an international, multidisciplinary, peer reviewed, open access journal.

\title{
Rolling Shutter Effect on the Accuracy of Photogrammetric Product Produced by Low-Cost UAV
}

\section{Abdullah Harun INCEKARA., Dursun Zafer ŞEKER}

\author{
Chief in Editor \\ Prof. Dr. Cem Gazioğlu \\ Co-Editors \\ Prof. Dr. Dursun Zafer Şeker, Prof. Dr. Şinasi Kaya, \\ Prof. Dr. Ayşegül Tanık and Assist. Prof. Dr. Volkan Demir
}

Editorial Committee (December 2021)

\begin{abstract}
Assoc. Prof. Dr. Abdullah Aksu (TR), Assit. Prof. Dr. Uğur Algancı (TR), Prof. Dr. Bedri Alpar (TR), Assoc. Prof. Dr. Aslı Aslan (US), Prof. Dr. Levent Bat (TR), Prof. Dr. Paul Bates (UK), İrşad Bayırhan (TR), Prof. Dr. Bülent Bayram (TR), Prof. Dr. Luis M. Botana (ES), Prof. Dr. Nuray Çağlar (TR), Prof. Dr. Sukanta Dash (IN), Dr. Soofia T. Elias (UK), Prof. Dr. A. Evren Erginal (TR), Assoc. Prof. Dr. Cüneyt Erenoğlu (TR), Dr. Dieter Fritsch (DE), Prof. Dr. Çiğdem Göksel (TR), Prof.Dr. Lena Halounova (CZ), Prof. Dr. Manik Kalubarme (IN), Dr. Hakan Kaya (TR), Assist. Prof. Dr. Serkan Kükrer (TR), Assoc. Prof. Dr. Maged Marghany (MY), Prof. Dr. Michael Meadows (ZA), Prof. Dr. Nebiye Musaoğlu (TR), Prof. Dr. Masafumi Nakagawa (JP), Prof. Dr. Hasan Özdemir (TR), Prof. Dr. Chryssy Potsiou (GR), Prof. Dr. Erol Sarı (TR), Prof. Dr. Maria Paradiso (IT), Prof. Dr. Petros Patias (GR), Prof. Dr. Elif Sertel (TR), Prof. Dr. Nüket Sivri (TR), Prof. Dr. Füsun Balık Şanlı (TR), Prof. Dr. Uğur Şanlı (TR), Duygu Ülker (TR), Prof. Dr. Seyfettin Taş (TR), Assoc. Prof. Dr. Ömer Suat Taşkın (TR), Assist. Prof. Dr. Tuba Ünsal (TR), Dr. Manousos Valyrakis (UK), Dr. İnese Varna (LV), Dr. Petra Visser (NL), Prof. Dr. Selma Ünlü (TR), Assoc. Prof. Dr. Oral Yağcı (TR), Prof. Dr. Murat Yakar (TR), Assoc. Prof. Dr. İ. Noyan Yılmaz (AU); Assit. Prof. Dr. Sibel Zeki (TR)
\end{abstract}

Abstracting and Indexing: TR DIZIN, DOAJ, Index Copernicus, OAJI, Scientific Indexing Services, International Scientific Indexing, Journal Factor, Google Scholar, Ulrich's Periodicals Directory, WorldCat, DRJI, ResearchBib, SOBIAD 


\title{
Rolling Shutter Effect on the Accuracy of Photogrammetric Product Produced by Low- Cost UAV
}

\author{
Abdullah Harun Incekara, ${ }^{1,+}$, Dursun Zafer Seker ${ }^{2}$ D \\ ${ }^{1}$ Department of Geomatics Engineering, Faculty of Engineering and Architecture, Tokat Gaziosmanpasa University, Tokat, Turkey \\ ${ }^{2}$ Department of Geomatics Engineering, Faculty of Civil Engineering, Istanbul Technical University, Istanbul, Turkey
}

* Corresponding author: A. H. Incekara

Received:06.06.2021

E-mail: abdullah.incekara@gop.edu.tr

Accepted: 06.11.202

How to cite: Incekara and Şeker (2021). Rolling Shutter Effect on the Accuracy of Photogrammetric Product Produced by Low-Cost UAV.

International Journal of Environment and Geoinformatics (IJEGEO), 8(4): 549-553, doi. 10.30897/ijegeo. 948676

\begin{abstract}
Low-level cameras are generally used in low-cost UAVs employed for photogrammetric product generation. Although such cameras have advantageous features in terms of flight time and maneuverability thanks to their light weight in a compact structure, they have also some limitations. These sensors are generally operated by rolling shutter which affects the image geometry. Unlike global shutter, a camera with rolling shutter creates a photograph by scanning line by line. In this study, two flights were performed by means of DJI Phantom 4 Pro to investigate the rolling shutter effect on the accuracy of photogrammetric product. Study area was a part of approximately 60 ha of Tasliciftlik Campus, Tokat Gaziosmanpasa University. Average speeds of the platform during photography were $8 \mathrm{~m} / \mathrm{sec}$ and $12 \mathrm{~m} / \mathrm{sec}$. Obtained data were evaluated according to SfM workflow. The orthophotos of the study area were produced from aerial photographs both with and without rolling shutter correction by using photogrammetric software. 24 ground control points located in the study area were used to strength the model and to make accuracy assessment. According to the results, total root mean square error values were improved from $6.33 \mathrm{~cm}$ to $4.78 \mathrm{~cm}$ and $7.01 \mathrm{~cm}$ to $4 \mathrm{~cm}$ for the flights pertaining to the $8 \mathrm{~m} / \mathrm{sec}$ and $12 \mathrm{~m} / \mathrm{sec}$, respectively. Thus, it can be said that better accuracy values can be obtained when rolling shutter correction are implemented during the process. Lower speeds may require multiple flight tasks depending on the extents of the study area. Therefore, it is more reasonable to fly at higher speeds and then apply rolling shutter correction to complete field work in less time.
\end{abstract}

Keywords: Accuracy, Aerial Photogrammetry, Global Shutter, Rolling Shutter, SfM

\section{Introduction}

Unmanned aerial vehicles (UAV) or drones are used for both hobby and commercial purposes. Competition with increasing diversity in the market and the compactness of the devices which provides sufficient quality photographs caused the rise in the number of the users. This increase naturally occurred not only in the population that was somehow close to the UAV-related practices (generally related with earth sciences) but also at different environments (Bayırhan and Gazioğlu, 2020; Gazioğlu et al., 2017).

When two photogrammetric products with different accuracy are jointly examined, they can be very compatible with each other in terms of visuality. 3D models, orthophotos, elevation models such as digital surface model and digital terrain model can be produced by means of aerial photographs obtained from low-level cameras mounted on the UAVs and all these are used in varied sectors (Karataş and Altınışık, 2020). However, visual attractiveness may lead to incorrect or incomplete interpretation of products by people who are not familiar with the factors affecting quantitative accuracy. Lack of background of many job groups in evaluating possible error sources causes specific issues such as shutter type to be excluded.
Factors affecting the accuracy of the final product in terms of quantitative in applications performed with UAV have been discussed in many aspects such as UAV type (Tahar and Ahmad, 2013), flight parameters (Dandois et al., 2015; Mesas-Carrascosa et al., 2016), image quality (Wierzbicki et al; 2015), image type (Amrullah et al.,2016) and variation of ground control points (GCP) (Martinez-Carricondo et al., 2018; Ren et al., 2020). Many studies with similar purposes are available in the literature. Apart from these, a topic has been addressed by very few researchers, which is the shutter type of the nonmetric camera. In Structure from Motion (SfM)photogrammetry, sufficient accuracy in terms of quality and quantity can be achieved when appropriate conditions are ensured, even with amateur devices. However, lowlevel aerial cameras are often embedded to low-cost UAVs due to maximum flight efficiency and their limited capacity. These sensors are generally operated by rolling shutter which affects the image geometry.

The main task of a shutter in a camera is to control the amount of light reaching the sensor. The shutter of a camera determines how and when light is recorded. In today's cameras there are basically two different shutter types: global and rolling. A camera with global shutter works on the principle of completing the capture of a photograph of interest at once as. However, this process 
spreads over a period of time in a camera with rolling shutter, which is called line-by-line scanning as can be illustrated in Fig. 1. In other words, the most obvious
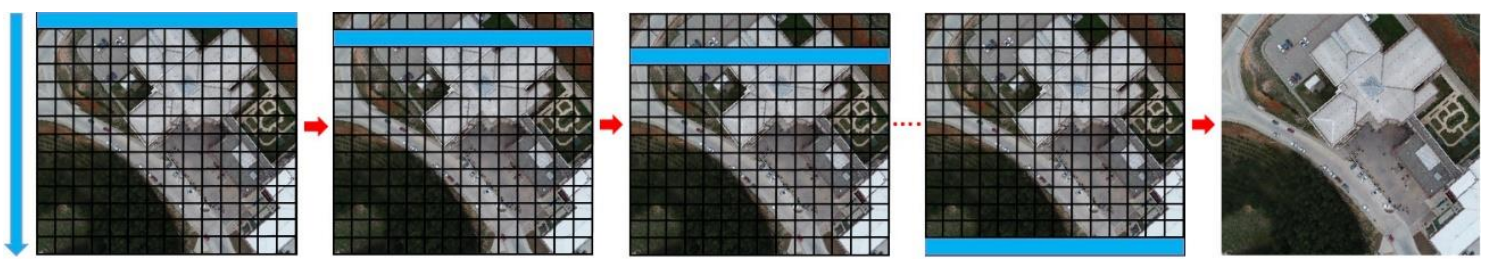

(a)
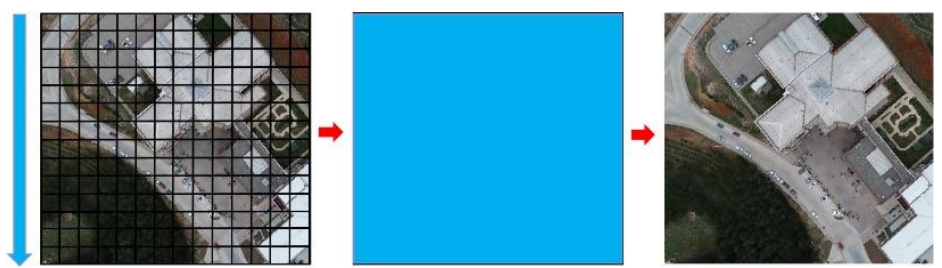

(b)

Fig. 1: Rolling shutter (a) and global shutter (b) operating systems

The possible negative effect of the rolling shutter system is spatial distortion. This effect becomes more pronounced in cases where image reading cannot keep up with the speed of moving objects. Distortion occurs in the image because the camera with rolling shutter cannot adequately respond to the speed of the object compared to the global shutter. This is often exemplifying by a rotating helicopter or ventilator propeller, guitar string, spinning tire, and similar objects. Therefore, as the speed increases, severity of the rolling shutter effect increases and the quality of the image decreases. On the contrary, all pixels in the captured image by using global shutter corresponds to the exactly same time of exposure. To better understanding of the effect caused by rolling shutter, Fig. 2 and Fig. 3. represents the comparison of the rotating propeller (Url-1) and high-speed railway (Url-2).

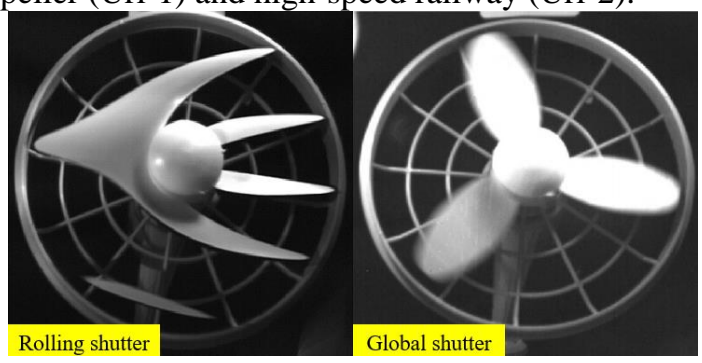

Fig. 2. Comparison of shutter types for rotating car tire (Wäny and Israel, 2003)

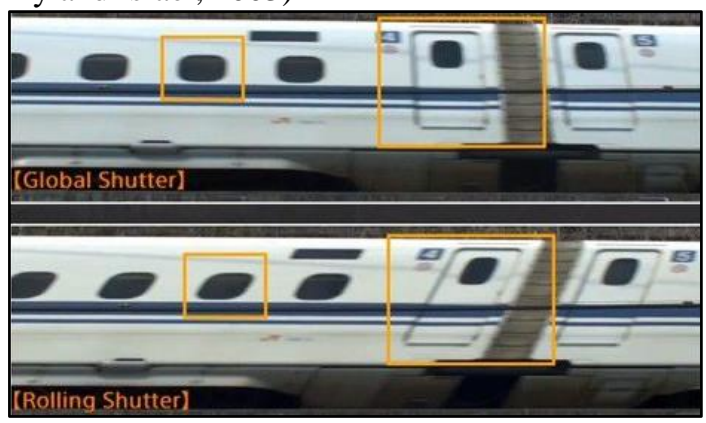

Fig. 3. Comparison of shutter types for high-speed railway (Url-1).
When considered in terms of photogrammetry, what is moving for the rolling shutter effect changes. In the examples mentioned above, the camera is stationary and there is a moving object. The object does not have to be movable for the rolling shutter effect to occur.

In UAV photogrammetry, the area of interest is stationary and the moving one is the camera integrated into the device. The resulting spatial distortion is not as visibly evident as with a spinning propeller or wheel. However, in a methodology where the final product is produced by deriving from optical data, it affects the final accuracy. Since there is a distortion in the geometric structure of the image, evaluating the data as if there is no rolling shutter effect may result in higher error values. As can be understood from the sample project reports of Pix4D (Url2), RMS error for the final product can be improved by means of rolling shutter correction. These reports belong the applications performed by using DJI Phantom 4 and DJI Inspire 1; however, study area was about 6 ha and the number of GCPs were 5 and 4 for different projects. In a limited number of studies, information was given about the type and importance of shutter such as Letessier et al. (2015), Lao et al. (2018) and Deng et al. (2018). Study carried out by Vautherin et al. (2016) investigated the rolling shutter effect on the mapping accuracy by using 8 GCPs distributed on the area of interest. Zhou et al. (2020) investigated the rolling shutter effect in UAV photogrammetry with a more complex study and proposed a mathematical correction approach. In order to test the contribution of rolling shutter correction on the mapping accuracy more clearly, more comprehensive application in terms of the distribution and number of control points was carried out. In this context, it was examined whether the rolling shutter correction has positive effect on the mapping accuracy after the flights performed at different speeds in an area of approximately 60 ha with 24 GCP. 


\section{Materials and Methods}

Materials and methods include the description of the study area and application involving field work and processing the data obtained in the field.

\section{Study Area}

Study area was a part of the Tasliciftlik Campus of Tokat Gaziosmanpasa University, Turkey which is presented in Fig. 4. This area covers an area of approximately 60 ha including 5 academic buildings and various administrative buildings. There are roads, trees, forest and bare soil surfaces at different heights. Thus, it can be said that rolling shutter effect was investigated in a changing roughness of topography. Region along the GCP 1 to 21 represents the lowest heights in the study area while region around the GCP 6 has the highest heights. 24 GCPs were used in the application. Actually, almost 40 points are located in the covered area but some of them is invisible in the photographs due to trees and some of them was destroyed during the construction operations in the campus area.

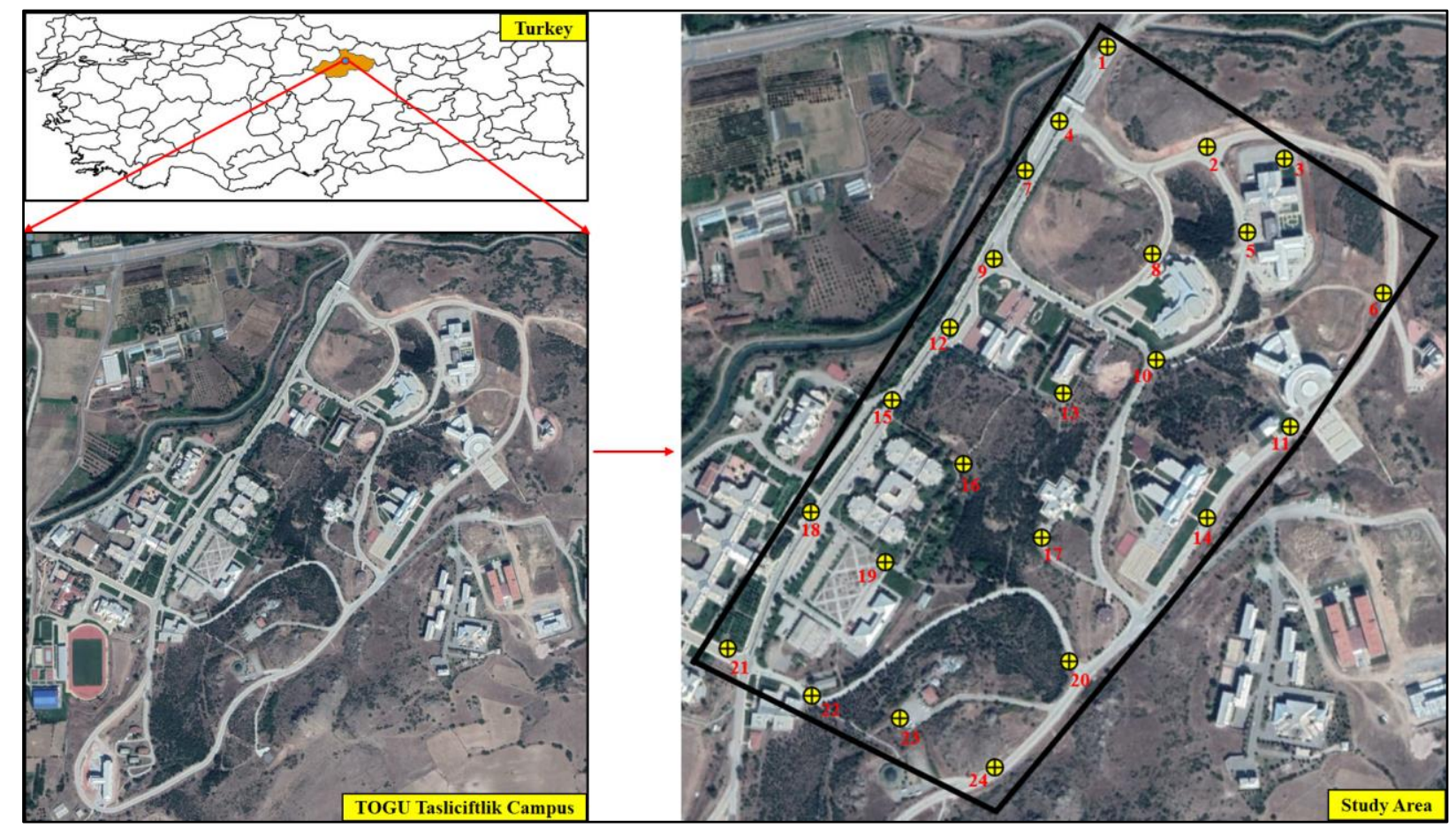

Fig. 4. Study area

In the scope of the study, DJI Phantom 4 Pro was used to collect aerial photographs of the campus. It is a smallsized instrument with a weight of approximately $1400 \mathrm{gr}$ including battery and propeller. Although it is mentioned in DJI website that the Phantom 4 pro has a mechanical shutter feature, the sensor of its camera is CMOS recording each image line by line. Thanks to the almost 30-minute flight time it offers, this device is used by many users for their hobby intentions, but it can also be preferred in several engineering practices due to its data acquisition capabilities and flight possibility at different heights assisted by its global positioning system (GPS) module. Even if the capability of the GPS modules mounted on this type of low-cost UAVs are limited to meter level due to their single frequency, the model can be strengthened with the help of GCPs installed on the area of interest. The GCPs in the study area are the points established to be used in the courses within the scope of undergraduate education of the Geomatics Engineering Department. Point coordinates were determined by GNSS measurements performed on previously established points.

Two flight tasks were carried out with a flight height of $150 \mathrm{~m}$. This value corresponds to the height from the takeoff point which was the near the GCP 14 and platform position in the air. Overlap rates in all directions were the same in both flight plans. The main difference between two flights was the platform speed. The average speed throughout the flight was $8 \mathrm{~m} / \mathrm{sec}$ on the first flight and 12 $\mathrm{m} / \mathrm{sec}$ on the other.

Agisoft Photoscan software was used to process the data to apply the SfM procedure. Data regarding both speeds were processed with and without rolling shutter compensation. Thus, 4 separate projects were generated. After the first alignment of the photographs, weak point cloud was produced. Points matching with each other were detected between consecutive photographs and the camera position of each photograph was estimated. Then each photograph was marked with the GCPs seen within the area covered and integrated with their $3 \mathrm{D}$ coordinates. Although some points except these 24 points were destroyed during the construction works in the campus and invisibility by the trees, available ones can characterize the topography. Contrast of GCPs with the ground and their appearance in the photograph are illustrated in Fig. 5. Based on the camera positions and GCPs, dense point clouds were produced by densification of the weak point cloud. Data processing was completed with optimization of camera positions and orthophoto production. 


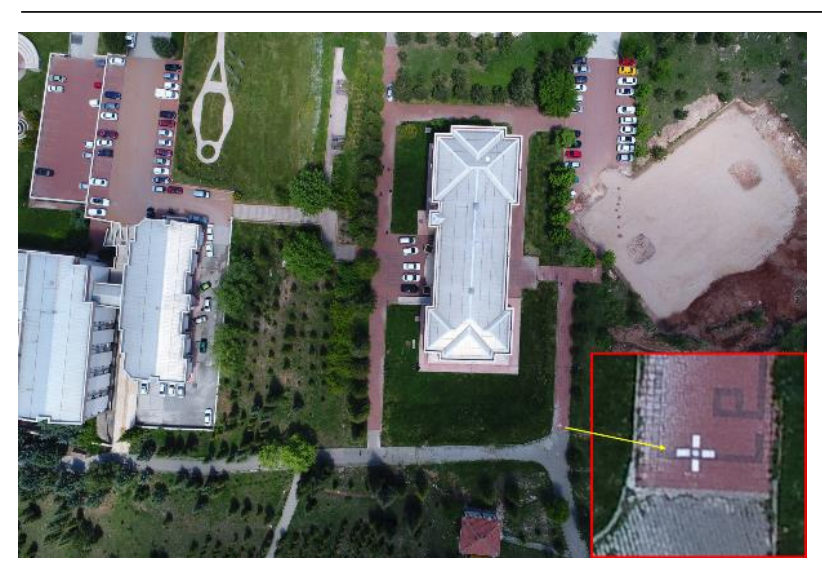

Fig. 5. View of GCP in the photograph

\section{Results}

Effect of rolling shutter on the image and mapping accuracy were evaluated by means of accuracy assessment. There are two types of spatial accuracy when SfM application is performed: Interior accuracy and exterior accuracy. The error calculation made directly via GCPs corresponds to the internal accuracy. However, for exterior accuracy, error calculation is made by means of check points in the model which was optimized with a certain number of GCPs. Thus, internal accuracy refers to the consistency the model within itself and exterior accuracy is more efficient in terms of reliability of the results. However, study carried out by MartinezCarricondo et al. (2018) proved that if the points are distributed all over the area homogeneously, interior accuracy based on all GCPs are sufficient not only in terms of planimetry but also altimetry. Therefore, interior accuracy assessment was made for all models based on the formulas given below:

$$
\begin{gathered}
R M S E_{X}=\sqrt{\frac{\sum_{i=1}^{n}\left(X_{i_{\text {model }}}-X_{\left.i_{G N S S}\right)^{2}}\right.}{n}} \\
R M S E_{Y}=\sqrt{\frac{\sum_{i=1}^{n}\left(Y_{i_{\text {model }}}-Y_{\left.i_{G N S S}\right)^{2}}\right.}{n}} \\
R M S E_{X Y}=\sqrt{\left(R M S E_{X}\right)^{2}+\left(R M S E_{Y}\right)^{2}} \\
R M S E_{Z}=\sqrt{\frac{\sum_{i=1}^{n}\left(z_{i_{\text {model }}}-Z_{\left.i_{G N S S}\right)^{2}}\right.}{n}} \\
R M S E_{\text {Total }}=\sqrt{R M S E_{X Y^{2}}+R M S E_{Z^{2}}}
\end{gathered}
$$

where:

RMSE is the root mean square error,

$\mathrm{n}$ is the number of GCPs used,

$X_{\text {imodel }}$ is the GCP coordinate of point $i$ on the X-axis,

$Y_{\text {imodel }} i$ s the GCP coordinate of point $i$ on the $Y$-axis,

$Z_{\text {inodel }}$ is the GCP coordinate of point $i$ on the Z-axis,

$R M S E_{X Y}$ is the horizontal accuracy,

$R M S E_{Z}$ is the vertical accuracy, and

$R M S E_{\text {Total }}$ is the total accuracy.

\section{Discussion and Conclusion}

The results with and without correction at different speeds were evaluated to determine the effect of rolling shutter correction. The results obtained from the values in the $\mathrm{x}$ and y directions indicate planimetric accuracy. It doesn't matter to interpret the error values in the $\mathrm{x}$ and $\mathrm{y}$ directions separately. The value obtained from the $\mathrm{z}$ direction corresponds to the accuracy of the altimetry.

Considering the flight performed with a speed of $8 \mathrm{~m} / \mathrm{sec}$, planimetric accuracy was improved from $3.89 \mathrm{~cm}$ to 2.9 $\mathrm{cm}$ after the rolling shutter compensation. Similarly, this value was improved from the $4.92 \mathrm{~cm}$ to $3.2 \mathrm{~cm}$ for the data belonging to the flight of $12 \mathrm{~m} / \mathrm{sec}$. Therefore, the effect of rolling shutter correction was greater at high speed in terms of planimetric accuracy.

When the vertical accuracy is evaluated, the error value improved from $5 \mathrm{~cm}$ to $3.8 \mathrm{~cm}$ after rolling shutter correction in the $8 \mathrm{~m} / \mathrm{sec}$ application. This change is from $5 \mathrm{~cm}$ to $2.4 \mathrm{~cm}$ in higher speed application. Therefore, as with planimetric accuracy, the effect of rolling shutter correction was more pronounced at higher speed in altimetry accuracy.

For the total error, these values were improved from 6.33 $\mathrm{cm}$ to $4.78 \mathrm{~cm}$ and $7.01 \mathrm{~cm}$ to $4.0 \mathrm{~cm}$, respectively. Although the speeds were $8 \mathrm{~m} / \mathrm{sec}$ and $12 \mathrm{~m} / \mathrm{sec}$, the difference in terms of the amount of total error improvement was almost double. Generally, it can be said that rolling shutter affects the geometric structure of the photographs and applying correction makes the results better.

In the uncorrected rolling shutter application, a better overall accuracy was obtained for $8 \mathrm{~m} / \mathrm{sec}$ since the geometric distortion in each image is less, which is what it should be. When rolling shutter correction is not applied, accuracy was expected to be lower in the applications where the platform was faster, which the Table 1 supports this situation. However, after introducing the rolling shutter correction, better results were obtained in terms of overall accuracy in the application performed with higher speed.

Table 1. Accuracy assessment for the projects $(\mathrm{cm})$

\begin{tabular}{lccc}
\hline Project Information & RMSE $_{\mathrm{x}}$ & $\mathrm{RMSE}_{\mathrm{y}}$ & $\mathrm{RMSE}_{\mathrm{z}}$ \\
\hline $8 \mathrm{~m} / \mathrm{sec}$ without RS & 2,8 & 2,7 & 5,0 \\
$8 \mathrm{~m} / \mathrm{sec}$ with RS & 2,1 & 2,0 & 3,8 \\
$12 \mathrm{~m} / \mathrm{sec}$ without RS & 3,0 & 3,9 & 5,0 \\
$12 \mathrm{~m} / \mathrm{sec}$ with RS & 2,0 & 2,5 & 2,4 \\
\hline
\end{tabular}

Results regarding projects without rolling shutter revealed that its effect is much more at higher speeds. However, a contradiction can be seen in altimetry results after the rolling shutter compensation. There was further improvement in the data, which was thought to have suffered further deterioration due to speed. A similar result for altimetry were obtained in the study performed by Vautherin et al. (2018). For better evaluation, more points may be included in the accuracy assessment after flights to be made at a time when invisible GCPs in the study area become usable. Oniga et al. (2018) mentioned that there should be $1 \mathrm{GCP}$ per $200 \mathrm{~m}^{2}$ in the area of interest but this ratio for the point density corresponds to the thousands of points in this study. This is contrary to the short duration of field work, which is one of the main advantages of photogrammetry. Another factor that 
causes a paradox in altimetry results may be originated from one of the factors affecting the accuracy of the final product in terms of quantitative in applications performed with UAV which was explained in the introduction section of the paper.

It is currently difficult to determine at what speeds and at what heights the rolling shutter correction should be used. Considering that the effect of the correction is clearer in the higher-speed application in the study, rolling shutter compensation may not be needed at speeds lower than 8 $\mathrm{m} / \mathrm{sec}$. However, as the flight altitude increases, the accuracy will decrease due to the numerical increase in the GSD value. In addition, low level UAVs at higher altitudes will be more difficult to stabilize, so image distortion will be more. Therefore, even if it is not necessary in low flights, it will be beneficial to bring the correction in case of high flight altitudes in terms of better results.

In this study, one battery was enough to complete the flight at once for both $8 \mathrm{~m} / \mathrm{sec}$ and $12 \mathrm{~m} / \mathrm{sec}$. Vautherin et al. (2016) also employed flights with $1 \mathrm{~m} / \mathrm{sec}$ and $4 \mathrm{~m} / \mathrm{sec}$. At very low speeds, the shutter type will not have much impact on the photograph and is likely to require more flights to cover the study area. Instead, it makes more sense to fly at higher speeds and then apply rolling shutter compensation. A comparison of results with flights at much higher speeds than $8 \mathrm{~m} / \mathrm{sec}$ and $12 \mathrm{~m} / \mathrm{sec}$ when the other factors are as identical as possible will reveal the rolling shutter effect more clearly. In future studies, the effect of rolling shutter correction on the results can be revealed even more clearly with point distribution variations in topographically different terrains.

\section{References}

Amrullah, C. Suwardhi, D., Meilano, I. (2016). Product accuracy effect of oblique and vertical non-metric digital camera utilization in UAV-photogrammetry to determine fault plane, ISPRS Annals of the Photogrammetry, Remote Sensing and Spatial Information Sciences, III-6, 41-48.

Bayırhan, I., Gazioğlu, C. (2020). Use of Unmanned Aerial Vehicles (UAV) and Marine Environment Simulator in Oil Pollution Investigations, Baltic J. Modern Computing, 8(2), 327-336, DOI: 10.22364/bjmc.2020.8.2.08.

Dandois, J.P. Olano M., Ellis, E.C. (2015). Optimal altitude, overlap, and weather conditions for computer vision UAV estimates of forest structure, Remote Sensing, 7, 13895-13920.

Deng, L. Mao, Z. Li, X. Hu, Z. Duan, F., Yan, Y. (2018). UAV-based multispectral remote sensing for precision agriculture: a comparison between different cameras, ISPRS Journal of Photogrammetry and Remote Sensing, 146, 124-136.

Gazioğlu, C., Varol, ÖE., Şeker, DZ., Çağlar, N. (2017). Determination of the Environmental Impacts of Marine Accidents Using UAV and RS Technologies, 19th MESAEP Symposium on Environmental and Health Inequity, Roma, ITALYA, 3-6 Dec 2017.

Karataş, K., Altınışık, N. S. (2020). The Effect of UAV Usage on Detail Points in Cadastre Update Studies: Çorum-Karaköy Case Study, International Journal of Environment and Geoinformatics, 7(2), 140-146, doi.10.30897/ijegeo.646155

Lao, Y. Ait-Aider, O., Araujo, H. (2018). Robustified Structure from Motion with rolling-shutter camera using straightness constraint, Pattern Recognition Letters, 111, 1-8.

Letessier, T.B. Juhel, J.B. Vigliola, L., Meeuwig, J. (2015). Low-cost small action cameras in stereo generates accurate underwater measurements of fish, Journal of Experimental Marine Biology and Ecology, 466, 120-126.

Martínez-Carricondo, P. Agüera-Vega, F. CarvajalRamírez, F. Mesas-Carrascosa, F.J. García-Ferrer, A., Pérez-Porras, F.J. (2018). Assessment of UAVphotogrammetric mapping accuracy based on variation of ground control points, International Journal of Applied Earth Observation and Geoinformation, 72, 1-10.

Mesas-Carrascosa F.J. García, M.D.N. Meroño de Larriva, J.E., García-Ferrer, A. (2016). An analysis of the influence of flight parameters in the generation of unmanned aerial vehicle orthomosaics to survey archaeological areas, Sensors, 16, 1838.

Oniga, V.E. Breaban, A.I. Statescu, F. (2018). Determining the optimum number of ground control points for obtaining high precision results based on UAS images, Proceedings, 2 (352), 1-11.

Ren, H. Zhao, Y. Xiao, W. Wang, X., Sui. T. (2020). An improved ground control point configuration for digital surface model construction in a coal waste dump using an unmanned aerial vehicle system, ISPRS Journal of Photogrammetry and Remote Sensing, 160, 51-66.

Tahar, K.N., Ahmad, A. (2013). An evaluation on fixed wing and multi-rotor UAV images using photogrammetric image processing, International Journal of Computer Information Engineering, 7 (1), 48-52.

Vautherin, J. et al. (2016). Photogrammetric accuracy and modeling of rolling shutter cameras, ISPRS Annals of the Photogrammetry, Remote Sensing and Spatial Information Sciences, Volume III-3, 139-146.

Wäny, M., Israel G.P. (2003). CMOS image sensor with NMOS-only global shutter and enhanced responsivity, IEEE Transactions on Electron Devices, 50(1), 57-62.

Wierzbicki, D. Kedzierski, M., Fryskowska, A. (2015). Assessment of the influence of UAV image quality on the orthophoto production, The International Archieves of the Photogrammetry, Remote Sensing and Spatial Information Sciences, XL-1/W4, 1-7.

Url-1:https://www.diyphotography.net/sony-sharespreviews-of-global-shutter-on-cmos-sensors-andsuper-low-light-technology/

Url-2:https://www.pix4d.com/blog/rolling-shuttercorrection 